\title{
Validation of the Psychometric Properties of the NEO-FFI-3 in an Arabic Context
}

\author{
Reem I Rabadi $\mathbb{I}^{\prime}$ \\ Alexander D Rabadi iD ${ }^{2}$ \\ 'School of Applied Humanities and \\ Languages, German Jordanian University, \\ Amman, III90, Jordan; ${ }^{2}$ School of \\ Medicine, The University of Jordan, \\ Amman, I1942, Jordan
}

\begin{abstract}
Aim: The present study aims to assess the validity and reliability of the psychometric properties of the Arabic adaptation of the NEO Five-Factor Inventory (NEO-FFI-3) to be used in research of personality inventory in the Arabic context.

Methods: It is a validation study of an Arabic version (NEO-AR) of the NEO-FFI-3. An online version was used to collect 1306 samples using convenient sampling in two phases. The collected data tested the validity of the inventory by using exploratory factor analysis (EFA) and confirmatory factor analysis (CFA), while reliability was verified using Cronbach's alpha after an Arabic version was conjured using forward translation, testing, and back-translation.

Results: The principal axis factoring (PAF) and the confirmatory factor analysis (CFA) are the analyses used to validate the factorial structure of the NEO-FFI-3 (NEO-AR). The reproduction of the original structure of NEO-FFI was proven using PAF, and CFA revealed a satisfactory fit of single-factor models for the five dimensions. The reliability analysis showed high values of internal consistency, which are congruent with previous international adaptations of the NEO-FFI-3.

Conclusion: The findings of the current study suggest that the Arabic version of the NEOFFI-3 (NEO-AR) is a reliable and robust instrument to measure the five dimensions of personality of the Five-Factor Model facets as the original North America NEO-FFI-3. The results imply that the approach measuring psychological characteristics is successful across different cultures as in previous studies and the Arab World in this study.
\end{abstract}

Keywords: NEO-FFI-3, personality, psychometrics, Arabic context, Big Five personality traits, personality inventory, validity

\section{Introduction}

Personality traits are interrelated to several life outcomes such as psychiatry, health, success, school and work performance, or language learning. ${ }^{1}$ The patterns of individual traits have led to studies that are essential to the development of trait psychology. ${ }^{1}$ Although not all psychologists were absolute with the importance of traits; conversely, research findings showed the universality and importance of personality traits. ${ }^{1}$ The aim of detecting and predicting individuals' behavior, feeling, and thinking motivate the scientific inspection of personality. ${ }^{2}$ It is believed personality traits are relatively consistent patterns of behaviors, feelings, and opinions in different circumstances and moments in time. ${ }^{2}$ They are what personality can be described by self-reports, ratings, or scales measure, and they include other components as standpoints, faiths, life experience, and motivations. ${ }^{3}$

Most of the research relating to personality traits has established the theory of the Big Five Traits (BFT) named by Goldberg (1992), which describes and explains
Correspondence: Reem I Rabadi School of Applied Humanities and Languages, German Jordanian University, Amman, II 190, Jordan

Email reem.rabadi@gju.edu.jo 
the behavior of humans. ${ }^{4,5}$ The stem of the BFT was from the use of adjectives that usually denote personality traits in English and other natural languages. ${ }^{6}$ A range of questionnaires was developed to gauge the five traits (domains) of the BFT model, which proposes Agreeableness (A), Conscientiousness (C), Extraversion (E), Neuroticism $(\mathrm{N})$, and Openness to experience (O). ${ }^{7}$ Agreeableness (A) shows the qualities of empathy, altruism, kindness, cooperation, and acquiescence. Conscientiousness (C) characterizes individual differences in being punctual, determined, systematic, respectful, and trustworthy. Extraversion (E) reveals individual differences in sociability, decisiveness, positive emotionality, and excitement seeking. Neuroticism (N) indicates the degree of anxiety, negative feelings, low self-esteem, and emotional stability. Finally, Openness to experience (O) reflects individual differences in innovation, curiosity, self-determining, and social attitudes. ${ }^{8,9}$

Different questionnaires of the BFT model led to the Five-Factor Model (FFM), identified as the Big Five with the five personality domains of the BFT., ${ }^{2,10,11}$ The Big Five traits are a universal language of personality and universal descriptions of personality across cultures and environments. ${ }^{3}$ Research on the BFI has led to the development and modification of two broad sets of measures, which are the Big Five Inventories (BFI-44, BFI-10, and BFI-2) $)^{2,10,11}$ and the NEO Inventories (NEO-PI, NEO-PI -R, NEO-FFI, NEO-PI-3, and NEO-FFI-3). ${ }^{2,10,11}$ These are the two operational tools for the FFM. The Revised NEO Personality Inventory (NEO-PI-R) and the NEOFive- Factor Inventory (NEO-FFI) developed by Costa and McCrae (1992) are the two most commonly used NEO inventories. ${ }^{12}$ The internal consistency levels of the NEO-PI-R are high, and researchers proved its validity. ${ }^{13}$ The structure of the NEO-PI-R can be considered universal as it can be found across different languages and cultures. $^{2}$ It was translated into several Indo-European languages ${ }^{14}$ and other language families as Filipino, ${ }^{15}$ Korean, ${ }^{16}$ and Chinese. ${ }^{17}$

The 60-item NEO-FFI inventory is the shortened modified version of the 240-item NEO-PI-R because of the quest for a time-efficient measure of the FFM. Administering the NEO-PI-R needs 45 minutes to be completed, ${ }^{18}$ whereas the NEO-FFI takes about 15 minutes to be finished. ${ }^{18,19}$ The NEO-FFI is regarded as one of the most accepted measures of the FFM. ${ }^{20}$ The reliability and validity of the NEO-FFI have been established in the North American context ${ }^{21}$ and other cultures. ${ }^{19}$ Moreover, the reproduction of the structure of the NEO-FFI has been found stable across different cultures. ${ }^{19,22}$

The NEO Five-Factor Inventory-3 (NEO-FFI-3) inventory is the revised version of the NEO-FFI intended for respondents who are not native English speakers for better comprehension. ${ }^{8}$ It comprises 60 items selected to assess only the five factors of personality traits. A five-point Likert scale is used for responses, from strongly agree to strongly disagree. ${ }^{8}$ The validity and Cronbach's alpha reliability have been confirmed for its subscales across studies. $^{23,24}$

The psychometric qualities of the NEO-PI-R, NEOFFI, and the NEO-FFI-3 have presented a robust verifica-

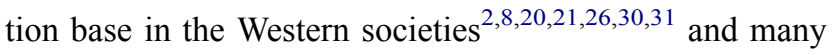
cross-cultural studies including different cultures in the world. ${ }^{13,15-17,19,22,23,25,27-29}$ The replication of the structure of NEO Inventories in Indo and non- Indo European languages provides strong evidence of their universality. Unfortunately, the researchers did not find any Arabic adaptation of the psychometric measures of the NEO-FFI -3 Inventory.

\section{Purpose of the Study}

The NEO-FFI-3 provides information on five personality domains: Agreeableness, Conscientiousness, Extraversion, Neuroticism, and Openness to experience. This inventory has been repeatedly found across ages, different languages, and cultures except for the Arabic language. This inventory is intended for employment, learning, and personal counseling settings involving activities such as career counseling, career development, employee training, shaping academic achievement, and guidance to learning styles where these five domains are the main focus.

The Arabic language differs from the English language and other languages in many respects. Arabic-speaking countries are diglossic caused by the use of two varieties of Arabic. Modern Standard Arabic (al-Fușhā)Arabic-speaking countries. Arabic is a highly inflectional morphological language as nouns, pronouns, and adjectives are inflected for gender, number, and case, while verbs are inflected for person, number, gender, tense, mood, and voice. As a result of these significant linguistic differences, Arabic contributes a substantial test of the universality of the NEO-FFI-3.

The purpose of the present study is to provide an Arabic validated version of the NEO-FFI-3 to meet the research demands of personality inventory in the Arabic context. This study utilizes the NEO-FFI-3 because its 
psychometric properties are somewhat better than the original inventory measurement, and some items from the original scale causing comprehension problems to adult respondents were eliminated in this inventory. ${ }^{20}$

\section{Materials and Methods}

\section{Instrumentation}

The original North American NEO-FFI-3 materials were purchased from Psychological Assessment Resources Incorporated (PAR Inc), Lutz Florida, USA4, for research and not for diagnostic applications as an Arabic adaptation of NEO-FFI 3 is not available in the literature to measure the Big Five personality traits in the Arab Region. The NEO-FFI-3 packet included item booklets (the questionnaire forms), answer sheets, and a Professional Manual. The two forms of the item booklet were Form $\mathrm{S}$ for selfreports and Form $\mathrm{R}$ for observer ratings, in addition to two types of answer sheets: hand-scorable (HS) sheet and scannable-scorable (SS) sheet. Form S item booklets and hand-scorable answer sheets were used in this study with internal consistencies ranging from 0.72 to 0.82 for the five factors. ${ }^{20}$

\section{The Arabic Translation}

The 60 items of NEO-FFI-3 were forward-translated from English to Modern Standard Arabic (al-Fuṣhā) by two expert Jordanian bilingual language specialists fluent in English with various social sciences backgrounds to produce two versions (AR-FFI-1 and AR-FFI-2). The two versions were compared by 20 volunteered subjects majoring in English translation to read and compare the two versions. Afterward, the translated items were edited and reviewed to improve clarity, comprehension, and appropriateness by the reader to be understandable across all Arabic- speaking countries as some terms may differ across countries. Lastly, a third translator with high English proficiency and native Arabic fluency applied a blind back-translation to both edited versions; then the results were compared to the original English North American NEO-FFI-3. The analysis of the back translation indicated some minor changes in translating four items $(21,26,34,56)$ to adjust them to their meaning in Arabic. For example, item 21, "I laugh easily" was translated into Arabic in such a way to yield the backtranslation "I laugh effortlessly" (أضحك دون عناء), whereas forward translation for this item was (أضحك بسهولة) which was the chosen translation. The items closest to the original were placed in the tested Arabic version used in this study.

The final Arabic version (AR-FFI) was tested using exploratory factor analysis (EFA) and confirmatory factor analysis (CFA) to test the validity, while reliability was verified using Cronbach's alpha.

\section{Participants and Procedures Participants}

A total of 653 undergraduate students enrolled in different universities in Jordan were included in the study for the exploratory factor analysis; a second sample size was obtained for the confirmatory factor analysis. Accepting responses were kept open until the second sample size reached 653 participants. Thus, an appropriate sample size for a sufficient power was collected. All participants were over 18 years old; their ages ranged from 18 to 25 , with a mean age of 22.4 and a standard deviation of 4.15 . The majority were females, with a percentage of $69 \%$. All participants had completed their secondary education successfully and have native fluency in the Arabic Language. The students were selected based on their willingness to participate in the online questionnaire as it was a convenience sampling method. All volunteers had the chance to withdraw from the questionnaire at any time; all questionnaires with missing data were discarded systematically based on an exclusion criterion on missing responses and outliers, which offset the data based on what was conducted in the previous studies ${ }^{13,17}$ to maintain a normal distribution for each item.

\section{Procedures}

The Arabic version (AR-FFI) was piloted among 16 students from different Jordanian universities; they were not involved in the study. In the piloting, the feasibility, simplicity, and time required to answer the questionnaire were evaluated. The problems with the tests were avoided.

A posted online link was accessible on various social media websites and forums of Jordanian university students. A cover page showed the purpose of the questionnaire and the main aims of the study. The initial page of the questionnaire showed the informed consent, which was taken from all participants before filling out the questionnaire. Participants' privacy was preserved in this study by dealing with the data anonymously. They were notified about the purpose of the study, and the data was only 
used for research purposes, thereby assuring the research was adherent to the Declaration of Helsinki 1989.

The questionnaire did not include personal data. Sociodemographic variables were asked as gender, age, current academic major, the current university enrolled in, and academic performance in university and their secondary education, followed by the AR-FFI 60-item questionnaire consisting of a 5-point Likert scale from 0 to 4: 0 (strongly disagree), 1 (disagree), 2 (neutral), 3 (agree), and 4 (strongly agree) (see Appendix 1). The data collected were used, without any manipulation or statistical correction, to perform the statistical analyses. The average time to complete the questionnaire was 18 minutes.

Finally, 42 questionnaires needed to be discarded due to unfilled questions or outliers in the dataset to maintain a normal Gaussian distribution and prevent disruption of the findings.

\section{Results}

Statistical analyses were performed using SPSS version 25 (IBM Inc., Armonk, NY, USA). The statistical software using STATA 15. (Stata Statistical Software: Release 15. College Station, TX: StataCorp LLC; USA) was used to carry out the confirmatory factor analysis. Kaiser-MeyerOlkin Test of Sampling Adequacy (KMO) and Bartlett's Test of Sphericity were utilized to measure the factorability of the inter-correlation matrix. Their results showed that the factor model was appropriate with a KMO value of 0.87 and a significant Bartlett's test of $\mathrm{p}<0.01$.

Descriptive statistics were conducted for the 60 items to show the mean values and standard deviation for the first sample size collected as shown in Table 1. Then, construct validity of the questionnaire was examined through exploratory factor analysis (EFA). Principal axis formatting was the method of choice for the 60 items. It was found that the items were sufficient, and there was no need to exclude any item from the study. The sample size entered in the eigenvalue matrix calculator to assess the eigenvalue, which should have a value greater than 1.0. Therefore, five eigenvalues were found to have a value greater than 1, which enhanced the assumption of a fivefactor model. These factors accounted for $57 \%$ of the variance of the scale.

The relationships between each of these five factors were first assumed to be correlated with each other. The factor analysis was repeated with a fixed factor number of 5 with oblique rotation and another with an orthogonal rotation. The direct oblimin rotation yielded correlation values lower than the correlation values of the orthogonal rotation (varimax) that was used as indicated in the rotated factor matrix with the exclusion of any value less than 0.3 as displayed in Table 2.

Varimax rotation was the chosen rotation to continue the factor analysis. The factor transformation matrix of the five eigenvalues is shown in Table 3 to compare the correlation between them.

The 60 items of the NEO-FF-I-3 are grouped to represent the Big Five personality traits (Extraversion, Neuroticism, Openness, Agreeableness, Conscientiousness). The translated items grouped like the original English items were items 26, 21, 6, 51, 46, 56, 41, 42, 11, 31, 47, 36 grouped Factor 1 which corresponded with Extraversion, while items 12, 16, 1, 17, 49, 37, 4, 34, 7, 32, 38, 19 grouped to Factor 2 which corresponded with Conscientiousness, while items 13, 60, 40, 2, 22, 28, 54, $25,15,10,50,20$ clustered to Factor 3 which corresponded with Neuroticism, while items 55, 35, 30, 45, $52,5,53,3,39,27,29,44$ clustered to Factor 4 which corresponded with Agreeableness, and items 24, 57, 14, $58,33,18,48,43,23,8,9,59$ clustered to Factor 5 which corresponded with Openness. Thus, matching the original items corresponding to their respective factors in the North American version exactly.

Confirmatory Factor Analysis was used to confirm the factor structure of the NEO-AR found in EFA using the second sample size collected. Based on the results of the EFA, a five-factor model of NEO-AR with 60 facets was illustrated as the five latent variables, each corresponding to their 12 facets and their errors with standard loading values and correlation values as shown in Figure 1.

The goodness-of-fit indices in STATA were used to check the effectiveness of the translated model. To estimate an upper limit of fit in the present data, the researchers conducted an estimated maximum likelihood Factor Analysis (EMLFA) with the same sample, extracting five orthogonal factors. All 120 fixed parameters in the CFA were then set at those EMLFA values to generate goodness-of-fit indices. Goodness-of-fit-indices used were $\chi^{2} / d f$ (ratio of Chi-Square divided by the respective degrees of freedom), Adjusted Goodness of Fit Index (AGFI), Incremental Fit Index (IFI), Tucker-Lewis index (TLI), comparative fit index (CFI), root mean square error of approximation (RMSEA), and confidence interval (90\% CI). The CFA results indicated that all the goodness-offit indices were above the cutoff points (see Table 4). 
Table I Descriptive Statistics

\begin{tabular}{|c|c|c|c|}
\hline & Mean & Std. Deviation & Analysis $\mathbf{N}$ \\
\hline Item I & 2.12 & 1.095 & 653 \\
\hline Item 2 & 2.11 & 1.078 & 653 \\
\hline Item 3 & 2.55 & 1.133 & 653 \\
\hline Item 4 & 3.25 & 0.739 & 653 \\
\hline Item 5 & 3.00 & 0.899 & 653 \\
\hline Item 6 & 1.28 & 1.227 & 653 \\
\hline Item 7 & 2.65 & 1.030 & 653 \\
\hline Item 8 & 1.73 & 1.228 & 653 \\
\hline Item 9 & 1.32 & 1.116 & 653 \\
\hline Item 10 & 2.19 & 1.104 & 653 \\
\hline Item II & 2.07 & 1.238 & 653 \\
\hline Item 12 & 1.26 & 1.165 & 653 \\
\hline Item 13 & 2.71 & 1.039 & 653 \\
\hline Item I4 & 1.62 & 1.183 & 653 \\
\hline Item 15 & 1.53 & 1.165 & 653 \\
\hline Item 16 & 1.86 & 1.212 & 653 \\
\hline Item 17 & 2.93 & 0.857 & 653 \\
\hline Item 18 & 2.19 & 0.861 & 653 \\
\hline Item 19 & 2.56 & 1.061 & 653 \\
\hline Item 20 & 2.96 & 0.972 & 653 \\
\hline Item 21 & 2.26 & 1.130 & 653 \\
\hline Item 22 & 2.38 & 1.041 & 653 \\
\hline Item 23 & 1.89 & 1.274 & 653 \\
\hline Item 24 & 1.26 & $1.17 \mid$ & 653 \\
\hline Item 25 & 2.46 & 1.032 & 653 \\
\hline Item 26 & 1.30 & 1.287 & 653 \\
\hline Item 27 & 2.81 & 1.003 & 653 \\
\hline Item 28 & 2.10 & 1.320 & 653 \\
\hline Item 29 & 2.73 & 1.009 & 653 \\
\hline Item 30 & 2.56 & 1.109 & 653 \\
\hline Item 3I & 1.91 & 1.115 & 653 \\
\hline Item 32 & 2.41 & 1.048 & 653 \\
\hline Item 33 & 1.73 & 1.110 & 653 \\
\hline Item 34 & 2.80 & 0.909 & 653 \\
\hline Item 35 & 2.37 & 0.957 & 653 \\
\hline Item 36 & 1.85 & I.I 27 & 653 \\
\hline Item 37 & 2.61 & 0.949 & 653 \\
\hline Item 38 & 3.06 & 0.973 & 653 \\
\hline Item 39 & 1.85 & I.207 & 653 \\
\hline Item 40 & 3.15 & 0.875 & 653 \\
\hline Item 4I & 1.81 & 1.208 & 653 \\
\hline Item 42 & 1.32 & 1.152 & 653 \\
\hline Item 43 & 2.31 & 1.288 & 653 \\
\hline Item 44 & 2.46 & 1.057 & 653 \\
\hline Item 45 & 1.28 & 1.101 & 653 \\
\hline Item 46 & 1.86 & 1.133 & 653 \\
\hline Item 47 & 1.37 & 1.189 & 653 \\
\hline Item 48 & 1.14 & I.I40 & 653 \\
\hline Item 49 & 2.91 & 0.918 & 653 \\
\hline Item 50 & 2.65 & 0.873 & 653 \\
\hline Item 5 I & 1.94 & 1.230 & 653 \\
\hline
\end{tabular}

(Continued)
Table I (Continued).

\begin{tabular}{|l|c|c|c|}
\hline & Mean & Std. Deviation & Analysis N \\
\hline Item 52 & 2.31 & 1.047 & 653 \\
Item 53 & 2.84 & 0.942 & 653 \\
Item 54 & 2.36 & 1.228 & 653 \\
Item 55 & 1.18 & 1.057 & 653 \\
Item 56 & 1.85 & 1.299 & 653 \\
Item 57 & 2.10 & 1.234 & 653 \\
Item 58 & 2.22 & 1.121 & 653 \\
Item 59 & 0.91 & 1.132 & 653 \\
Item 60 & 3.04 & 0.938 & 653 \\
\hline
\end{tabular}

Consequently, the CFA confirmed the factor structure of the NEO-AR, which was generated by EFA.

The reliability of the five factors was calculated using Cronbach's apha. Factor 1 (Extraversion) showed a correlation of 0.73 , Factor 2 (Conscientiousness) showed a correlation of 0.76 , Factor 3 (Neuroticism) showed a correlation of 0.77, Factor 4 (Agreeableness) showed a correlation of 0.82 , and Factor 5 (Openness) showed a correlation of 0.74 . This reliability is consistent with the original reliability in the North American context has been confirmed with $\alpha$ ranging from 0.72 to 0.82 for the five factors. ${ }^{20}$

\section{Discussion}

This study provides a tool for future studies of potential relationships between the Big Five personality traits and a wide variety of factors in the Arab region. This tool is not only robust, time convenient in comparison to longer surveys but also easy to understand and relate to in the setting of the Arab culture.

The NEO Inventories are used across cultures to measure the five dimensions of personality. The present study assessed the psychometric properties of the Arabic NEOFFI, an instrument developed with items taken from the NEO-PI-R to meet the need for a shortened measure of personality in the Arab world. The results obtained with principal axis factoring and confirmatory factor analysis showed that the Arabic NEO-FFI is mainly equivalent to the original version developed by $\mathrm{McCrae}$ and Costa (2004) and further confirms that the five dimensions of personality are present in the Arab population. We maintain that the Arabic NEO-FFI should not be revised strictly according to the empirical factor loadings since the dimensions measured are broad and the losses in internal consistency do not harm the reliability of any element. Within 
Table 2 Comparison Between the Two Rotation Matrices

\begin{tabular}{|c|c|c|c|c|c|c|c|c|c|c|c|}
\hline \multicolumn{12}{|c|}{ Rotated Factor Matrix } \\
\hline & \multicolumn{5}{|c|}{ Factor } & & \multicolumn{5}{|c|}{ Factor } \\
\hline & $\mathbf{I}$ & 2 & 3 & 4 & 5 & & I & 2 & 3 & 4 & 5 \\
\hline Item 26 & 0.732 & & & & & Item 26 & 0.548 & & & & \\
\hline Item 2 I & 0.706 & & & & & Item 2I & 0.532 & & & & \\
\hline Item 6 & 0.624 & & & & & Item 6 & 0.479 & & & & \\
\hline Item $5 \mid$ & 0.62 & & & & & Item $5 \mid$ & 0.456 & & & & \\
\hline Item 46 & 0.588 & & & & & Item 46 & & & 0.451 & & \\
\hline Item 56 & 0.575 & & & & & Item 56 & 0.447 & & & & \\
\hline Item 4| & 0.574 & & & & & Item 4I & 0.443 & & & & \\
\hline Item 42 & 0.568 & & & & & Item 42 & 0.423 & & & & \\
\hline Item II & -0.536 & & & & & Item II & 0.414 & & & & \\
\hline Item 3| & 0.536 & & & & & Item 3I & 0.405 & & & & \\
\hline Item 47 & 0.509 & & & & & Item 47 & 0.402 & & & & \\
\hline Item 36 & 0.519 & & & & & Item 36 & & 0.612 & & & \\
\hline Item 12 & & 0.832 & & & & Item 12 & & 0.609 & & & \\
\hline Item 16 & & -0.828 & & & & Item 16 & & 0.549 & & & \\
\hline Item I & & 0.806 & & & & Item I & & 0.535 & & & \\
\hline Item 17 & & 0.771 & & & & Item 17 & 0.373 & & & & \\
\hline Item 49 & & 0.753 & & & & Item 49 & & & & 0.412 & \\
\hline Item 37 & & 0.725 & & & & Item 37 & & 0.5 .27 & & & \\
\hline Item 4 & & -0.673 & & & & Item 4 & & -0.473 & & & \\
\hline Item 34 & & 0.664 & & & & Item 34 & & 0.464 & & & \\
\hline Item 7 & & 0.639 & & & & Item 7 & & 0.439 & & & \\
\hline Item 32 & & 0.570 & & & & Item 32 & & & & & 0.328 \\
\hline Item 38 & & 0.564 & & & & Item 38 & & 0.438 & & & \\
\hline Item 19 & & 0.558 & & & & Item 19 & & 0.358 & & & \\
\hline Item 13 & & & 0.906 & & & Item 13 & & & 0.822 & & \\
\hline Item 60 & & & 0.861 & & & Item 60 & & & 0.817 & & \\
\hline Item 40 & & & 0.732 & & & Item 40 & & & 0.774 & & \\
\hline Item 2 & & & 0.621 & & & Item 2 & & & 0.695 & & \\
\hline Item 22 & & & -0.613 & & & Item 22 & & & -0.613 & & \\
\hline Item 28 & & & 0.610 & & & Item 28 & & & 0.610 & & \\
\hline Item 54 & & & 0.565 & & & Item 54 & 0.512 & & & & \\
\hline Item 25 & & & 0.511 & & & Item 25 & & & 0.511 & & \\
\hline Item 15 & & & 0.510 & & & Item 15 & & & 0.504 & & \\
\hline Item 10 & & & 0.503 & & & Item 10 & & & 0.495 & & \\
\hline Item 50 & & & 0.503 & & & Item 50 & & & 0.478 & & \\
\hline Item 20 & & & 0.502 & & & Item 20 & & & 0.461 & & \\
\hline Item 55 & & & & 0.826 & & Item 55 & & & & 0.658 & \\
\hline Item 35 & & & & 0.817 & & Item 35 & & & & 0.598 & \\
\hline Item 30 & & & & 0.773 & & Item 30 & & & & 0.582 & \\
\hline Item 45 & & & & 0.756 & & Item 45 & & & & 0.573 & \\
\hline Item 52 & & & & 0.713 & & Item 52 & & & & 0.556 & 0.527 \\
\hline Item 5 & & & & 0.628 & & Item 5 & & & & 0.531 & \\
\hline Item 53 & & & & 0.623 & & Item 53 & & & & 0.488 & \\
\hline Item 3 & & & & 0.611 & & Item 3 & & & & 0.452 & \\
\hline Item 39 & & & & 0.598 & & Item 39 & & & & 0.433 & \\
\hline Item 27 & & & & 0.582 & & Item 27 & & & 0.328 & 0.427 & \\
\hline Item 29 & & & & 0.577 & & Item 29 & & & & 0.408 & \\
\hline Item 44 & & & & 0.552 & & Item 44 & & & & 0.389 & \\
\hline Item 24 & & & & & 0.943 & Item 24 & & & & & 0.537 \\
\hline Item 57 & & & & & 0.927 & Item 57 & & & & & 0.532 \\
\hline Item 14 & & & & & 0.887 & Item 14 & & & & & -0.521 \\
\hline
\end{tabular}

(Continued) 
Table 2 (Continued).

\begin{tabular}{|c|c|c|c|c|c|}
\hline \multicolumn{6}{|c|}{ Rotated Factor Matrix } \\
\hline Item 58 & 0.834 & Item 58 & 0.421 & \multirow{9}{*}{0.493} & 0.519 \\
\hline Item 33 & 0.764 & Item 33 & & & 0.502 \\
\hline Item 18 & 0.720 & Item 18 & & & 0.475 \\
\hline Item 48 & 0.649 & Item 48 & & & \\
\hline Item 43 & 0.635 & Item 43 & & & 0.436 \\
\hline Item 23 & 0.612 & Item 23 & & & 0.412 \\
\hline Item 8 & 0.610 & Item 8 & & & 0.385 \\
\hline Item 9 & 0.576 & Item 9 & & & 0.367 \\
\hline Item 59 & 0.548 & Item 59 & & & 0.339 \\
\hline
\end{tabular}

Notes: Extraction method: principal axis factoring, varimax rotation. Rotation method: varimax with Kaiser normalization. Extraction method: principal axis factoring direct oblimin rotation. Rotation method: varimax with Kaiser normalization.

Table 3 Eigenvalue Rotated Transformation Matrix

\begin{tabular}{|l|c|c|c|c|c|}
\hline \multicolumn{5}{|l|}{ Factor Transformation Matrix } \\
\hline Factor & 1 & 2 & 3 & 4 & 5 \\
1 & -0.924 & 0.449 & 0.582 & -0.506 & -0.220 \\
2 & 0.583 & 0.951 & 0.649 & 0.433 & -0.349 \\
3 & 0.452 & -0.552 & 0.939 & 0.507 & 0.608 \\
4 & -0.715 & 0.649 & -0.753 & 0.851 & 0.897 \\
5 & -0.448 & 0.749 & -0.440 & 0.695 & 0.910 \\
\hline
\end{tabular}

Notes: Extraction method: principal axis factoring. Rotation method: varimax with Kaiser normalization.

the context of the original and adaptations of the NEOFFI, previous circumstances of mismatches of item loadings have been noted; the primacy was conferred to theoretical/conceptual aspects over empirical loadings. ${ }^{20}$

Exploratory factor analysis (EFA) is a statistical method chosen in this study to reveal the underlying structure of a relatively large set of variables and to identify the underlying relationships between measured variables. These measured variables are tested to observe if they influence the factors and how many factors exist (five in this study) through factor loadings and which variables affect which loading assuming that any measured variable may be associated with any factor. After associating the variables with the five factors, confirmatory factor analysis (CFA) is used to test that a relationship between the observed variables and their underlying latent factor exists by measuring the fitness of the model and capturing the covariance between all the items. The hypothesized five-factor model is put to the test in the Arabic context using this structural equation modeling method. These two methods measure the construct validity of the proposed questionnaire to figure if the translated items measure the five-factor model and the strength of association each item measure for its respective factor solely. Following, reliability is measured by using cronbach's alpha for each of the five factors.

The construct validity of the translated questionnaire was tested using exploratory factor analysis. The unidimensionality of the items was conserved as it was conducted in previous cross-cultural translation studies. ${ }^{15,32}$ Consequently, a Rasch analysis was not needed, so the classical test theory was used. The principal axis formatting was used after a thorough expert review and testing of the 60 items that were deemed, representative. Again, finding a five-factor model with the highest loading in a varimax rotation in comparison to previous NEO-FFI literature, which also used orthogonal rotations (varimax or procustes) ${ }^{33}$ directs that the sample size in this study presented a similar understanding of the items in Arabic like that understanding of North America's volunteers towards the original English version. ${ }^{15} \mathrm{~A}$ strong correlation in each of the five facets rivals that of the original English Version. ${ }^{20}$

Confirmatory factor analysis is an exclusive technique in Structural Equation Modeling (SEM) which utilizes confirmatory hypothesis testing. ${ }^{34}$ The $\chi^{2} / d f$ should be less than 4, AGFI, IFI, TLI, and CFI should be above 0.90 , and RMSEA should be less than 0.08 to indicate that the model is of-good-fit. ${ }^{35}$ Orthogonal rotation is chosen based on the assumption of no correlation between facets. However, the model suggests otherwise as it showed that some items represent different sides of a personality, and personalities tend to cluster rather than present as individual properties. ${ }^{15,32}$ A ratio of volunteers to items of more than 10:1 was used to ensure adequate measurement of the model. This high number also causes the Chi-square to overestimate. To avoid this conflict, the Tucker-Lewis index, comparative fit index, 


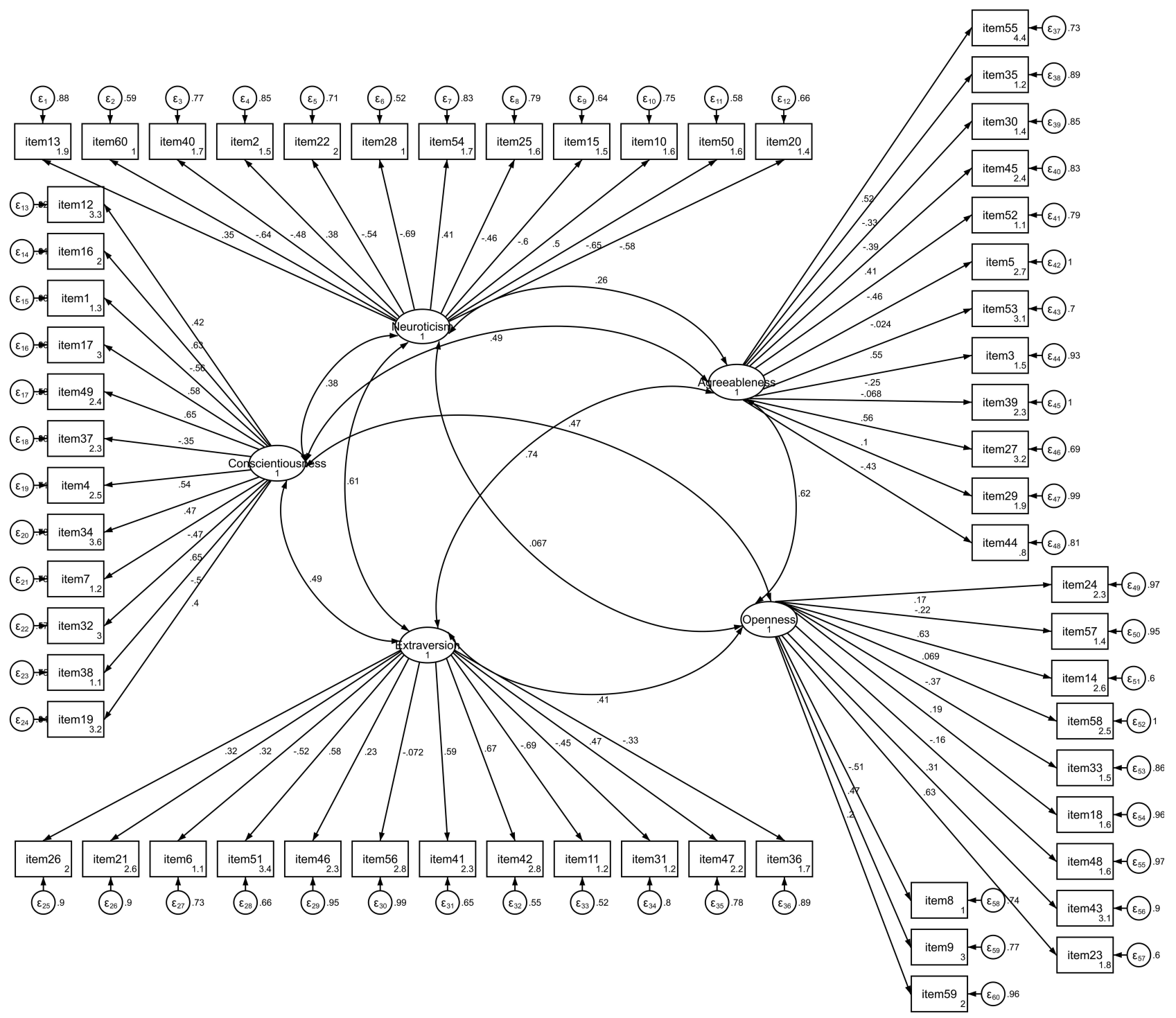

Figure I lllustrates the confirmatory factor analysis of the five latent variables with their respective factor loadings and error variance, as well as the covariance between them.

and root mean square error of approximation were taken into consideration for the goodness-of-fit of the model. The final model was concluded to be robust enough for future research purposes.

The results in the CFA where items $(2,13,37,26,21$, $46,56,36,59,43,48,18,58,57,24,29,39,3,53,35)$ had low factor loadings indicating these items are not associated with their respective factors. In McCrae 1996, the hypothesis of whether each of the factors was independent of each other or interrelated was studied indepth as it perplexed the experts how an oblique rotation which assumes no relationship between factors was the rotation that produced the highest factor loadings yet in the CFA, significant covariance was found indicating a relationship between the five factors. ${ }^{33}$ This hypothesis is enforced in this study once more when a varimax rotation was the chosen rotation in EFA, but covariance was included in the path analysis and with high loadings.

Table 4 Goodness-of-Fit Indices

\begin{tabular}{|l|c|c|c|c|c|c|c|}
\hline Fit index & $\chi \mathbf{2}(\mathbf{d} f)$ & AGFI & IFI & TLI & CFI & RMSEA & 90\% CI \\
\hline Acceptable range & $<4$ & & & & & \\
& 2.61 & 0.872 & 0.927 & 0.91 & 0.93 & 0.06 & $1.3-5.8$ \\
\hline
\end{tabular}


Values in the EFA are considered more trusted than in CFA generally.

\section{Conclusion}

It can be concluded that the product of this study has appropriate reliability and robustness to be utilized in future personality trait research in the Middle East and North Africa regions where Arabic is the mother tongue. The Arabic translation and adaptation of the NEO-FFI-3 (NEOAR) were proven to measure the five-factor model facets as the original North America NEO-FFI-3 has approved before. The results infer that the approach measuring psychological characteristics is successful across different cultures as in previous studies and the Arab World in this study.

One limitation of the present study is that it did not sample a general Arab adult population as the sample was compromised of Jordanian university students, this may have limited the generalizability of the findings of the study. Nevertheless, future research with Arab adult samples should test the generalizability of the current findings.

Another limitation is the age group the NEO-AR is intended for a specific age group as it is based on the original North American version, which needs a certain level of education to understand the meaning and answer accordingly. Thus, this instrument cannot be utilized in school-age groups before future research is conducted. The last limitation is that no criterion validity was measured as this study provides an adaptation of a well-studied instrument, and the results favor maintaining the current scale used until future studies are conducted to develop a more suited scale.

\section{Data Sharing Statement}

The data that support the findings of this study are available on request from the corresponding author.

\section{Disclosure}

The authors report no conflicts of interest in this work.

\section{References}

1. Costa PT Jr, McCrae RR, Löckenhoff CE. Personality across the life span. Annu Rev Psychol. 2019;4(70):423-448. doi:10.1146/annurevpsych-010418-103244

2. McCrae RR, Costa PT Jr. Personality trait structure as a human universal. Am Psychol. 1997;52(5):509-516. doi:10.1037/0003066X.52.5.509

3. Kunnel JR, Xavier B, Waldmeier A, Meyer A, Gaab J. Psychometric evaluation of the BFI-10 and the NEO-FFI-3 in Indian adolescents. Front Psychol. 2019;9(10):1057. doi:10.3389/fpsyg.2019.01057
4. Goldberg LR. The development of markers for the Big-Five factor structure. Psychol Assess. 1992;4(1):26-42. doi:10.1037/10403590.4.1.26

5. Patki SM, Abhyankar SC. Big-five personality factors as predictors of organizational citizenship behavior: a complex interplay. Int J Indian Psychol. 2016;3(2):137-146.

6. Zhou X, Saucier G, Gao D, Liu J. The factor structure of Chinese personality terms. J Pers. 2009;77(2):363-400. doi:10.1111/j.14676494.2008.00551.x

7. Rolland JP. The cross cultural generalizability of the five factors of personality. In: McCrae RR, Allik J, editors. The Five-Factor Model of Personality Across Cultures. New York: Springer ScienceBusiness Media; 2002:7-28.

8. Costa P, McCrae R. The revised NEO personality inventory (NEO-PI -R). In: Boyle GJ, Matthews G, Saklofske DH editors. The SAGE Handbook of Personality Theory and Assessment: Volume 2Personality Measurement and Testing. SAGE Publications Ltd; 2008:179-198.

9. Morizot J. Construct validity of adolescents' self-reported big five personality traits: importance of conceptual breadth and initial validation of a short measure. Assess. 2014;21(5):580-606. doi:10.1177/ 1073191114524015

10. Digman JM. Personality structure: emergence of the five-factor model. Annu Rev Psychol. 1990;41(1):417-440. doi:10.1146/ annurev.ps.41.020190.00222

11. John OP, Naumann LP, Soto CJ. Paradigm shift to the integrative bigfive trait taxonomy. In: John OP, Ronibs RW, Pervin LA, editors. Handbook of Personality: Theory and Research. New York: Guilford Press; 2008:114-158.

12. Costa PT, McCrae RR. Normal personality assessment in clinical practice: the NEO personality inventory. Psychol Assess. 1992;4 (1):5-13. doi:10.1037/1040-3590.4.1.5

13. McCrae RR, Terracciano A, Khoury B, et al. Universal features of personality traits from the observer's perspective: data from 50 cultures. J Pers Soc Psychol. 2005;88(3):547-561. doi:10.1037/00223514.88.3.547

14. McCrae RR, Costa PT, Del Pilar GH, et al. Age differences in personality across the adult life span: parallels in five cultures. Devel Psychol. 1999;35(2):466-477. doi:10.1037/0012-1649.35.2.466

15. McCrae RR, Costa PT, Del Pilar GH, Rolland JP, Parker WD. Crosscultural assessment of the five-factor model: the Revised NEO Personality Inventory. J Cross-Cult Psychol. 1998;29(1):171-188. doi:10.1177/0022022198291009

16. Piedmont RL, Chae JH. Cross-cultural generalizability of the five-factor model of personality: development and validation of the NEO-PI-R for Koreans. J Cross-Cult Psychol. 1997;28(2):131-155. doi:10.1177/0022022197282001

17. McCrae RR, Costa PT, Yik MS. Universal aspects of Chinese personality structure. In: Bond $\mathrm{MH}$, editor. The Handbook of Chinese Psychology. Hong Kong: Oxford University Press; 1996:189-207.

18. Fountoulakis KN, Siamouli M, Moysidou S, et al. Standardization of the NEO-PI-3 in the Greek general population. Ann Gen Psychiatry. 2014;13(1):36. doi:10.1186/s12991-014-0036-9

19. Aluja A, García Ó, Rossier J, García LF. Comparison of the NEO-FFI, the NEO-FFI-R and an alternative short version of the NEO-PI-R (NEO-60) in Swiss and Spanish samples. Pers Ind Dif. 2005;38(3):591-604. doi:10.1016/j.paid.2004.05.014

20. McCrae RR, Costa PT. A contemplated revision of the NEO Five-Factor Inventory. Pers Ind Dif. 2004;36(3):587-596. doi:10.1016/S0191-8869(03)00118-1

21. Costa PT, McCrae RR, Dye DA. Facet scales for agreeableness and conscientiousness: a revision of the NEO personality inventory. Pers and Ind Dif. 1991;12:887-898. doi:10.1016/0191-8869(91)90177-D

22. Lucas RE, Donnellan MB. Age differences in personality: evidence from a nationally representative Australian sample. Dev Psychol. 2009;45(5):1353-1363. doi:10.1037/a0013914 
23. McCrae RR, Costa PT. Brief versions of the NEO-PI-3. J Ind Dif. 2007;28(3):116-128. doi:10.1027/1614-0001.28.3.116

24. Marjanovic Z, Holden R, Struthers W, Cribbie R, Greenglass E. The inter-item standard deviation (ISD): an index that discriminates between conscientious and random responders. Per Ind Dif. 2015;84:79-83. doi:10.1016/j.paid.2014.08.021

25. Allik J, Realo A. Universal and specific in the five factor model of Personality. In: Widgier TA, editor. The Oxford Handbook of the Five Factor Model. New York: Oxford University Press; 2017:173-190.

26. O'Connor MC, Paunonen SV. Big Five personality predictors of post-secondary academic performance. Pers Ind Dif. 2007;43 (5):971-990. doi:10.1016/j.paid.2007.03.017

27. Abbas M, Khan MN. Big-five personality factors and emotional intelligence among university students: a gender perspective. Int J Res Stud Psychol. 2018;7:1-12. doi:10.5861/ijrsp.2017.2000

28. Karmakar R. Exploring the big five factor traits of college going adolescents. Biomed J Sci Tech Res. 2017;1(2):265-267. doi:10.26717/bjstr.2017.01.000170

29. Singh J, Ullah F. Personality factors as determinants of the stress experienced by the adolescents. Int J Ind Psychol. 2016;4(1):47-58. doi: $10.25215 / 0401.167$

30. Magalhães E, Salgueira A, Gonzalez AJ, et al. NEO-FFI: psychometric properties of a short personality inventory in Portuguese context. Psicologia: Reflexão e Crítica. 2014;27(4):642-657. doi:10.1590/1678-7153.201427405
31. Kallasmaa T, Allik J, Realo A, McCrae RR. The Estonian version of the NEO-PI-R: an examination of universal and culture-specific aspects of the five-factor model. Eur J Pers. 2000;14(3):265-278. doi:10.1002/1099-0984(200005/06)14:3<265::AID-PER376>3.0. $\mathrm{CO} ; 2-\mathrm{B}$

32. Rolland JP, Parker WD, Stumpf H. A psychometric examination of the French translations of the NEO PI-R and NEO-FFI. $J$ Pers Assess. 1998;71(2):269-291. doi:10.1207/s15327752jpa7102_13

33. McCrae RR, Zonderman AB, Costa PT, Bond MH, Paunonen SV. Evaluating replicability of factors in the revised NEO personality inventory: confirmatory factor analysis versus procrustes rotation. $J$ Pers Soc Psychol. 1996;70(3):552-566. doi:10.1037/00223514.70.3.552

34. Kline R. Convergence of structural equation modeling and multilevel modeling. In: Williams M, Vogt WP editors. The SAGE Handbook of Innovation in Social Research Methods. SAGE Publications Ltd; 2011:562-589. doi:10.4135/9781446268261.

35. MacCallum RC, Browne MW, Sugawara HM. Power analysis and determination of sample size for covariance structure modeling. Psycho Meth. 1996;1(2):130-149. doi:10.1037/1082-989X.1.2.130
Psychology Research and Behavior Management

\section{Publish your work in this journal}

Psychology Research and Behavior Management is an international, peer-reviewed, open access journal focusing on the science of psychology and its application in behavior management to develop improved outcomes in the clinical, educational, sports and business arenas. Specific topics covered in the journal include: Neuroscience, memory and decision making; Behavior modification and management; Clinical

\section{Dovepress}

applications; Business and sports performance management; Social and developmental studies; Animal studies. The manuscript management system is completely online and includes a very quick and fair peer-review system, which is all easy to use. Visit http://www. dovepress.com/testimonials.php to read real quotes from published authors. 